\section{Commentary: Expanded options for dialysis-dependent patients requiring valve replacement in the transcatheter era}

\author{
Alexander A. Brescia, MD, MSc, \\ Steven F. Bolling, MD, and Bo Yang, MD, PhD
}

In a meta-analysis of 10,164 patients in 24 observational studies, Chi and colleagues ${ }^{1}$ compare long-term survival, bleeding, and structural valve degeneration between mechanical versus bioprosthetic valves in patients undergoing surgical aortic valve replacement (AVR), mitral valve replacement (MVR), or double valve replacement. A long-term survival benefit was found for mechanical compared with bioprosthetic valves in the aortic position, but not the mitral position. As expected, mechanical valves conferred a higher risk of bleeding when international normalized ratio was $>2.5$ and structural valve degeneration was lower for mechanical valves. In contrast to prior metaanalyses, ${ }^{2,3}$ this study stratified outcomes by aortic versus mitral position, which is important for decision making. In addition, the study includes a large number of patients in this small, but high-risk group undergoing cardiac surgery. However, the study is unable to inform age-specific prognosis, which is essential to choosing a valve type. Additionally, it is unknown how many patients received anticoagulation therapy preoperatively for other indications, which could also influence valve selection.

The emergence of transcatheter options for valve replacement (transcatheter mitral valve replacement [TMVR] and transcatheter aortic valve replacement [TAVR]) has influenced the decision making process of valve choice for MVR and AVR. Although these data inform the choice of

From the Department of Cardiac Surgery, University of Michigan, Ann Arbor, Mich. Dr Brescia is supported by a National Research Service Award postdoctoral fellowship (No. 5T32HL076123).

Disclosures: The authors reported no conflicts of interest.

The Journal policy requires editors and reviewers to disclose conflicts of interest and to decline handling or reviewing manuscripts for which they may have a conflict of interest. The editors and reviewers of this article have no conflicts of interest.

Received for publication June 14, 2020; accepted for publication June 14, 2020; available ahead of print June 30, 2020.

Address for reprints: Alexander A. Brescia, MD, MSc, Department of Cardiac Surgery, Frankel Cardiovascular Center, University of Michigan, 1500 E Medical Center Dr, Ann Arbor, MI 48109 (E-mail: abrescia@med.umich.edu).

J Thorac Cardiovasc Surg 2022;163:2072-3

0022-5223/\$36.00

Copyright (c) 2020 by The American Association for Thoracic Surgery

https://doi.org/10.1016/j.jtcvs.2020.06.069

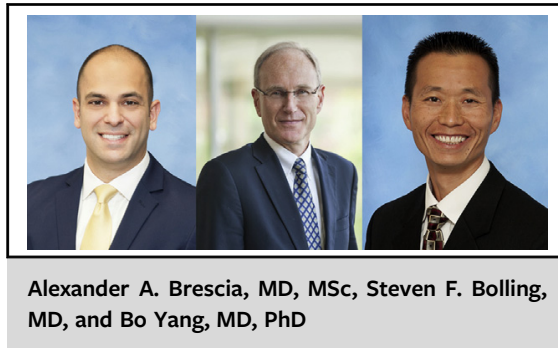

CENTRAL MESSAGE

The emergence of transcatheter options has influenced aortic and mitral valve replacement decision making and reinforced our preference for bioprosthetic over mechanical valves in dialysis patients.

surgical valve, TMVR and TAVR outcomes are not included and many studies in the meta-analysis took place before transcatheter options were routinely utilized. Accordingly, these data do not fully reflect the current decision-making process for dialysis-dependent patients.

For MVR, mechanical valves have been shown to carry an increased risk of thromboembolic complications and bleeding, but lower reoperation rate and potentially superior survival over bioprosthetic valves when performed in young patients. ${ }^{4}$ However, long-term survival estimates are not quantified in this meta-analysis of dialysis-dependent patients for whom prognosis is poor. ${ }^{1}$ Our preference for bioprosthetic MVR of unrepairable valves has been reinforced by the emergence of percutaneous, transcatheter, transseptal options for valve-in-valve TMVR, with excellent success and low rates of residual mitral regurgitation..$^{5-7}$ These transcatheter options for future reintervention have also lowered our threshold for choosing primary surgical replacement over repair for rheumatic valves with calcified, immobile anterior leaflets. ${ }^{8}$

We have implanted more than 2000 stentless aortic valve bioprostheses that were durable overall, but with an increased reoperation rate for patients younger than age 60 years. ${ }^{9}$ Reinterventions have included redo aortic root replacement, ${ }^{10}$ stented bioprostheses implanted into existing stentless bioprosthetic roots, and more than 100 TAVin-stentless procedures. Only 90 patients in the series were dialysis-dependent and 5-year survival was $<50 \%$. 
Because long-term prognosis for dialysis-dependent patients is poor, we prefer TAVR as our initial strategy for most of these patients.

Because in-hospital mortality is high and prognosis is so poor for dialysis patients undergoing surgical or transcatheter valve replacement, choosing a valve and approach to achieve short- and midterm success may be more important than basing the decision on long-term durability in these patients. For patients who do survive long term, we have successfully performed more than 250 TMVR and TAVR valve-in-valve procedures implanting transcatheter valves into failed surgical bioprostheses.

In conclusion, we commend the authors for this contribution and recommend transcatheter or surgical bioprostheses over mechanical valves for dialysis-dependent patients requiring MVR or AVR.

\section{References}

1. Chi K-Y, Chiang M-H, Kang Y-N, Li S-J, Chan Y-T, Chen Y-C, et al. Mechanical or biological heart valve for dialysis-dependent patients? A meta-analysis. $J$ Thorac Cardiovasc Surg. 2022;163:2057-71.e12.
2. Altarabsheh SE, Deo SV, Dunlay SM, Obeidat YM, Erwin PJ, Rababa'h A, et al. Tissue valves are preferable for patients with end-stage renal disease: an aggregate meta-analysis. J Card Surg. 2016;31:507-14.

3. Phan K, Zhao DF, Zhou JJ, Karagaratnam A, Phan S, Yan TD. Bioprosthetic versus mechanical prostheses for valve replacement in end-stage renal disease patients: systematic review and meta-analysis. J Thorac Dis. 2016;8:769-77.

4. Goldstone AB, Chiu P, Baiocchi M, Lingla B, Patrick WL, Fischbein MP, et al. Mechanical or biologic prostheses for aortic-valve and mitral-valve replacement. N Engl J Med. 2017;377:1847-57.

5. Yoon S-H, Whisenant BK, Bleiziffer S, Delgado V, Schofer N, Eschenbach L, et al. Transcatheter mitral valve replacement for degenerated bioprosthetic valves and failed annuloplasty rings. J Am Coll Cardiol. 2017;70:1121-31.

6. Takagi H, Hari Y, Kawai N, Ando T, ALICE (All-Literature Investigation of Cardiovascular Evidence) Group. A meta-analysis of valve-in-valve and valve-in-ring transcatheter mitral valve implantation. J Interv Cardiol. 2018; 31:899-906

7. Grover FL, Vemulapalli S, Carroll JD, Edwards FH, Mack MJ, Thourani VH, et al 2016 annual report of the Society of Thoracic Surgeons/American College of Cardiology transcatheter valve therapy registry. J Am Coll Cardiol. 2017;69:1215-30.

8. Brescia AA, Watt TMF, Murray SL, Rosenbloom LM, Kleeman KC, Allgeyer H, et al. Rheumatic mitral valve repair or replacement in the valve-in-valve era. $J$ Thorac Cardiovasc Surg. May 10, 2020 [Epub ahead of print].

9. Yang B, Malik A, Farhat L, Makkinejad A, Norton EL, Sarein MA, et al. Influence of age on longevity of a stentless aortic valve. Ann Thorac Surg. December 23, 2019 [Epub ahead of print].

10. Yang B, Patel HJ, Norton EL, Debenedictus C, Farhat L, Wu Z, et al. Aortic valve reoperation after stentless bioprosthesis: short- and long-term outcomes. Ann Thorac Surg. 2018;106:521-5.

\section{Commentary: Choice of valve prosthesis in dialysis-dependent patients: Should being on dialysis influence our recommendation?}

\author{
Afshin Ehsan, MD \\ Dialysis-dependent patients undergoing surgical valve \\ replacement have posed a dilemma with regard to choice \\ of valve prosthesis given their constant exposure to interven- \\ tions and limited life expectancy. This has often swayed \\ From The Warren Alpert Medical School of Brown University, Providence, RI. \\ Disclosures: The author reported no conflicts of interest. \\ The Journal policy requires editors and reviewers to disclose conflicts of interest and \\ to decline handling or reviewing manuscripts for which they may have a conflict of \\ interest. The editors and reviewers of this article have no conflicts of interest. \\ Received for publication June 18, 2020; accepted for publication June 23, 2020; \\ available ahead of print June 30, 2020. \\ Address for reprints: Afshin Ehsan, MD, The Warren Alpert Medical School of \\ Brown University, 2 Dudley St, Suite 360, Providence, RI 02905 (E-mail: \\ aehsan@lifespan.org). \\ J Thorac Cardiovasc Surg 2022;163:2073-4 \\ $0022-5223 / \$ 36.00$ \\ Copyright (c) 2020 by The American Association for Thoracic Surgery \\ https://doi.org/10.1016/j.jtcvs.2020.06.068
}

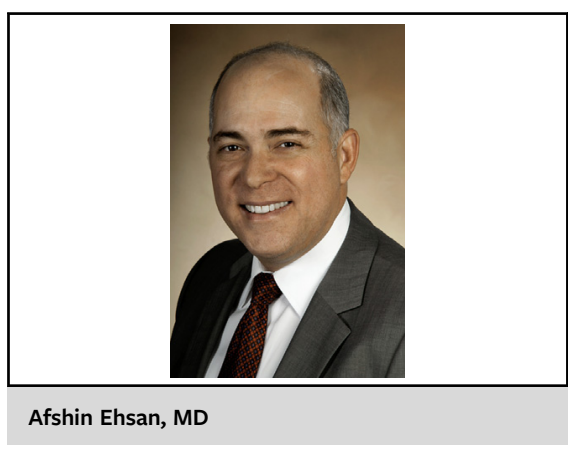

CENTRAL MESSAGE

The choice or recommendation of surgical valve prosthesis in dialysis-dependent patients should follow traditional guidelines without being influenced by the patient's need for dialysis.

surgeons to consider bioprosthetic valves even in younger patients. Chi and colleagues ${ }^{1}$ shed further light on this important clinical question as it relates to the management of this 